\title{
Developing Evidence-Informed Early Childhood Intervention E-Learning Lessons, Performance Checklists and Practice Guides
}

\section{Carl J. Dunst ${ }^{1}$ \\ Melinda Raab" \\ Davon Embler ${ }^{3}$ \\ Kaki Roberts ${ }^{4}$}

1,2,s, Orelena Hawks Puckett Institute, United States

'Email: cdunst@puckett.org.

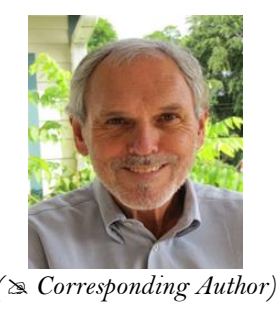

\section{Abstract}

The foundations for the content, design, and preparation of early childhood intervention elearning lessons, performance checklists, and practice guides are described. Methods and procedures described in the microlearning, professional development, early childhood intervention, expert performance, and product design literatures were used to develop an integrated framework for guiding product development. The framework includes six components based on research findings about the relationships between the integrated framework methods and procedures and how the confluence of research evidence informed the development of evidence-informed early childhood intervention products. The use of the framework is described and illustrated for two sets of e-learning lessons, performance checklists, and practice guides.

Keywords: E-Learning, Microlearning, Early childhood intervention, Product design, Expert performance.

JEL Classification: Education and research institutions.

Citation | Carl J. Dunst; Melinda Raab; Davon Embler; Kaki Roberts (2018). Developing Evidence-Informed Early Childhood Intervention E-Learning Lessons, Performance Checklists and Practice Guides. Journal of Education and e-Learning Research, $5(4): 242-248$.

History:

Received: 17 October 2018

Revised: 13 November 2018

Accepted: 20 December 2018

Published: 10 January 9019

Licensed: This work is licensed under a Creative Commons Attribution 3.0 License (c) ) E

Publisher: Asian Online Journal Publishing Group
Contribution/Acknowledgement: All authors contributed to the conception and design of the study. The contents and opinions expressed, however, are those of the authors and do not necessarily reflect the policy or official position of the U.S. Department of Education, Office of Special Education position of the U.S. Department of Education, Office of Special Education
Programs, University of Connecticut Health Center, or the Early Childhood Programs, University of Connecticut Health Center, or the Early Child
Personnel Center, and no endorsement should be inferred or implied.

Funding: The preparation of this paper was supported, in part, by funding from the U.S. Department of Education, Office of Special Education Programs (No. 325B120004) for the Early Childhood Personnel Center, University of Connecticut Health Center (Mary Beth Bruder, Principal Investigator).

Competing Interests: The authors declare that they have no conflict of interests.

Transparency: The authors confirm that the manuscript is an honest, accurate, and transparent account of the study was reported; that no vital features of the study have been omitted; and that any discrepancies from the study as planned have been explained.

Ethical: This study follows all ethical practices during writing.

\section{Contents}

1. Introduction 


\section{Introduction}

Lessons learned from more than 20 years of developing early childhood intervention materials and products for practitioners and parents informed the development of the methods and procedures described in this paper. Early childhood intervention (ECI) refers to the learning activities, experiences, and opportunities used with young children birth to 6-years-of-age with or without developmental disabilities or delays and their families (Dunst and Espe-Sherwindt, 2017; Sukkar et al., 2017). Exponential knowledge growth in ECI (Dunst, 2018a) has necessitated knowledge management and sharing in ways that increase ECI practitioner and family member adoption and use of evidence-informed ECI practices. Evidence-informed refers to the use of practice-based research evidence about the relationships between ECI practices and outcomes of interest to inform the content of ECI materials and products (Dunst, 2016; Nelson and Campbell, 2017).

The development of the e-learning lessons, performance checklists, and practice guides was based on research and practice informed by microlearning (Hug, 2016) evidence-based professional development (Dunst, 2015) evidence-based ECI practices (Dunst, 2017c) authentic e-learning experiences (Harrington et al., 2010) the role of deliberate practice in expert learning and performance (Ericsson, 2006) and best practices in e-learning lesson (Khan, 2005; Karagiannidis et al., 2014) and product (Lidwell et al., 2003) design. Table 1 shows the primary sources of information found most helpful in the design and development of e-learning lessons, performance checklists, and practice guides.

The e-learning lessons that have been the focus of our work are primarily web-based products. They are designed to be used by practitioner as self-guided learning tools (Athanasou, 2005; Beavers, 2009) or by a professional development specialists or course instructor to facilitate practitioner or student learning (Beavers $e t$ al., 2017). Performance checklists include "lists of tasks or steps required to complete a procedure [or practice] successfully... and serve as concrete reminders of which tasks need to be performed" to achieve desired outcomes or benefits (Wilson, 2013). Practice guides include the same content as e-learning lessons but are made available in a wide range of print and mobile device formats (Dunst et al., 2017).

Figure 1 shows the relationship between the three ECI products and the fact that they overlap and are expected to have intended outcomes or benefits when used together to influence practitioner or family member understanding and use of evidence-informed ECI practices. Research evidence about the key characteristics of ECI practices was used to select or develop performance checklist indicators (Dunst, 2017c).

Table-1. Sources of Information for the Development of Evidence-Informed Early Childhood Intervention Products

\begin{tabular}{|c|c|}
\hline Product Design & Representative Sources \\
\hline $\begin{array}{l}\text { Microlearning (Preparation of relatively small learning units that include } \\
\text { specific learning activities that can be completed in a short period of time) }\end{array}$ & $\begin{array}{l}\text { Buchem and Hamelmann (2010); } \\
\text { Hug (2016) }\end{array}$ \\
\hline $\begin{array}{l}\text { Evidence-Based Professional Development (Professional development } \\
\text { methods and procedures informed by research evidence for the effects of the } \\
\text { methods and procedures on learner outcomes) }\end{array}$ & $\begin{array}{l}\text { Dunst et al. }(2015) \\
\text { Dunst et al. }(2010)\end{array}$ \\
\hline $\begin{array}{l}\text { Early Childhood Intervention Practices (Planned or naturally occurring } \\
\text { activities, experiences, events, and learning opportunities that are } \\
\text { empirically } \\
\text { related to improvements or changes in child, parent, family, or practitioner } \\
\text { outcomes) }\end{array}$ & $\begin{array}{l}\text { Dunst (2016); } \\
\text { Dunst (2017a) }\end{array}$ \\
\hline $\begin{array}{l}\text { Authentic Adult Learning Activities (Learning activities that actively } \\
\text { involve learners in real-world experiences that provide opportunities for } \\
\text { improving understanding of the effects of intervention practices on } \\
\text { outcomes } \\
\text { of interest) }\end{array}$ & $\begin{array}{l}\text { Herrington et al. (2010); } \\
\text { Reeves et al. (2002) }\end{array}$ \\
\hline $\begin{array}{l}\text { Deliberate Practice (Learning experiences and opportunities that actively } \\
\text { engage learners in deliberate practice to facilitate and promote acquisition } \\
\text { of } \\
\text { expert performance) }\end{array}$ & $\begin{array}{l}\text { Ericsson (2006); } \\
\text { Ward et al. (2004) }\end{array}$ \\
\hline $\begin{array}{l}\text { Product Design (Preparation of e-learning and other products that are } \\
\text { learner- } \\
\text { centered and include and adhere to evidence-based design features [e.g., } \\
\text { principal of consistency]) }\end{array}$ & $\begin{array}{l}\text { Herrington (2006); } \\
\text { Lidwell et al. (2003) }\end{array}$ \\
\hline
\end{tabular}

Performance checklist indicators are, in turn, used to inform the content of the practices that are the focus of both e-learning lessons and practice guides (Dunst, 2017b). The content and organization of the practice guides are informed by best practices for reinforcing the content of the e-learning lessons (Ghirardini, 2011). The use of the elearning lessons, performance checklists, and practice guides by ECI practitioners is expected to improve child, family, or practitioner outcomes to the extent the practices are used with adherence and fidelity (Wolery, 2011; Hulleman and Kopp, 2012).

\section{Foundations for Product Development}

The sources of information in Table 1 were used to inform the development of the e-learning lessons and other ECI products by incorporating key concepts and practices from the different but compatible fields of product design and development. Principles from microlearning were used to chunk learning content into small units where the different units, taken together, include the key characteristics of evidence-informed ECI practices (Gobet et al., 2001). The methods and procedures used to facilitate practitioner learning are informed by evidence-based professional development practices (Dunst et al., 2010; Dunst et al., 2015) and evidence-informed ECI practices (Dunst, 2016). The learning activities and exercises in the ECI products include real-world examples that practitioners are likely to encounter as part of their professions where the learning activities include multiple opportunities for deliberate practice (Reeves et al., 2002). The preparation of all three ECI products (e-learning 
lessons, performance checklists, and practice guides) are informed by principles of product design (Lidwell et al., 2003).

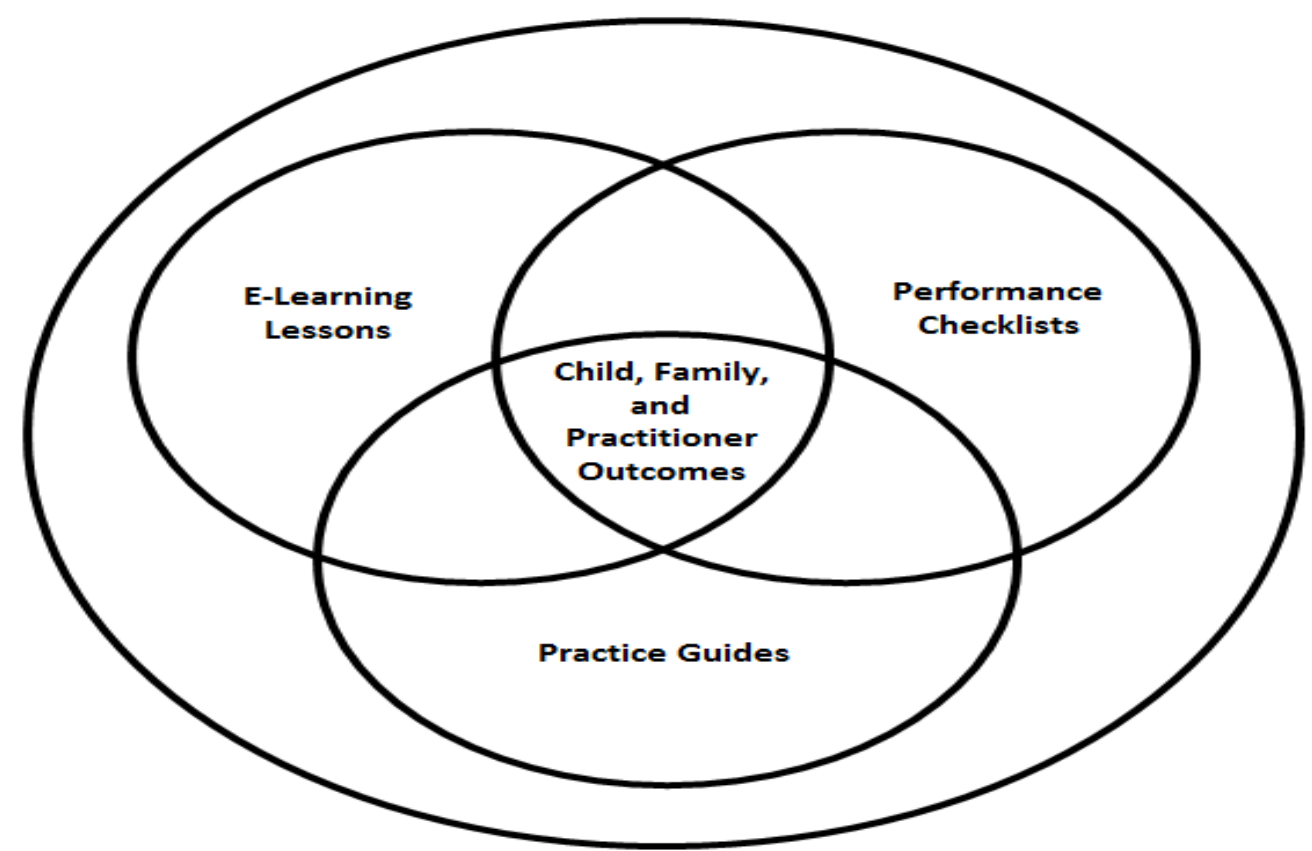

Figure-1. Interrelationships among the three sets of early childhood intervention practices and their effects of child, family, and practitioner outcomes

The ways in which the six sets of product design and development elements are related is shown in Figure 2. The methods, procedures, and principles that are the foundations for both microlearning and evidence-based professional development each include three sets of practices: (1) introduction and illustration or demonstration the use of an ECI practice, (2) a series of learner activities and exercises to engage a practitioner in the use of a practice, and (3) practitioner self-evaluation or professional development specialist/instructor facilitated learner reflection on his or her understanding and use of a practice.

\begin{tabular}{|c|c|c|}
\hline MICROLEARNING & $\begin{array}{l}\text { EVIDENCE-INFORMED } \\
\text { EARLY CHILDHOOD } \\
\text { INTERVENTION }\end{array}$ & PRODUCT DESIGN \\
\hline \multirow{5}{*}{$\begin{array}{l}\text { 1. Introduction, problem } \\
\text { definition, and task } \\
\text { description }\end{array}$} & PRACTICES & \multirow{5}{*}{$\begin{array}{l}\text { Principle of Consistency } \\
\text { Common Terminology } \\
\text { Content Sequencing } \\
\text { Layering } \\
\text { Interactivity } \\
\text { Instructional Videos }\end{array}$} \\
\hline & \multirow{4}{*}{$\begin{array}{l}\text { Child-Focused Practices } \\
\text { Parent-Focused Practices } \\
\text { Family-Focused Practices } \\
\text { Practitioner-Focused } \\
\text { Practices }\end{array}$} & \\
\hline & & \\
\hline & & \\
\hline & & \\
\hline $\begin{array}{l}\text { EVIDENCE-BASED } \\
\text { PROFESSIONAL } \\
\text { DEVELOPMENT }\end{array}$ & $\begin{array}{c}\text { PRACTITIONER } \\
\text { LEARNING ACTIVITIES }\end{array}$ & $\begin{array}{l}\text { EARLY CHILDHOOD } \\
\text { INTERVENTION } \\
\text { PRODUCTS }\end{array}$ \\
\hline 1. Introduction and & AuthenticLearning & E-Learning Lessons \\
\hline $\begin{array}{l}\text { 2. Learner activities and } \\
\text { self-evaluation }\end{array}$ & $\begin{array}{l}\text { Distributed Learning } \\
\text { Opportunities }\end{array}$ & Performance Checklists \\
\hline $\begin{array}{l}\text { 3. PDS or faculty-guided } \\
\text { learner reflection and } \\
\text { feedback }\end{array}$ & $\begin{array}{l}\text { Deliberate Practice to } \\
\text { Improve Performance }\end{array}$ & Practice Guides \\
\hline
\end{tabular}

Figure-2. Model for showing the relationships among the key features of product development and design. (NOTE. PDS = Professional development specialist.) 
Any number of evidence-informed ECI practices can be the focus of microlearning and evidence-based professional development. A practitioner's ability to learn to use a practice is facilitated by authentic learning experiences that include distributed learning opportunities embedded throughout the ECI products (e.g., (Reeves $e t$ al., 2002; Lidwell et al., 2003; Bersin, 2004)). Deliberate practice is used to improve learner performance for promoting practitioner expertise (Oblinger and Maruyama, 1996; Harrington et al., 2010).

A number of specific design principles and practices were explicitly used as part of ECI product development (e-learning lessons, performance checklists, and practice guides). These included the use of common terminology, content sequencing, layering, interactivity, and instructional videos to illustrate practitioner or parent use of the key characteristics of ECI practices. The principle of consistency was adhered to in terms of different products prepared in similar ways. As noted by Lidwell et al. (2003) the usability of different products is more "learnable when similar parts are expressed in similar ways. Consistency enables people to efficiently transfer knowledge to new contexts [and] learn new things quickly" (p. 56). The use of common terminology ensured that the same, similar, or common terms have the same meaning to facilitate learner understanding (Cabré, 1999; Thaiss and Zawacki, 2006; Brenes, 2017) and use of ECI practices (Rabin and Brownson, 2012; Colquhoun et al., 2014). Content sequencing was used to order learning content to improve learner understanding and integration of material within and between ECI products (Morrison et al., 2007). Layering was accomplished in terms of "organizing information into related groupings and then presenting or making available only certain groupings at any one time" (Lidwell et al., 2003). Interactivity was accomplished by incorporating as many exercises as possible into the e-learning lessons to actively engage learners in activities to promote understanding and mastery of the ECI practices (Wagner, 1997; Juwah, 2006).

Two types of instructional videos were embedded in all of the e-learning lessons: Microvideos and tutorial videos (Brunner, 2018). "Microvideos are short instructional videos that focus on teaching a single" specific practice (Brunner, 2018). These types of videos were used to illustrate the use of performance checklist practice indicators. Most of the microvideos are only 10 to 30 seconds in length for each checklist indicator although a few are about one-minute in length. This is consistent with research findings that short microvideos are most effective in terms of learner engagement (Guo et al., 2014; Wistia Learning Center, 2016). Tutorial videos were used to "walk [a learner] through the steps needed to complete a task" (Brunner, 2018). These videos were only 5 to 6 minutes long and illustrated how all of the practices on a performance checklist "go together" and constitute the key characteristics of a particular ECI practice. The length of the videos is based on research evidence that longer videos are related to attenuated learner engagement (Guo, 2013) and learning (Brame, 2015).

\section{Product Design and Development}

Our initial work focused primarily on the development of performance checklists (e.g., Raab and Dunst (2006)) and practice guides (Dunst et al., 2007). The reader is referred to Dunst (2018b) for compilations of both types of products. Our recent product development activities have focused on e-learning lessons, and how performance checklists and practice guides can be used, respectively, to inform e-learning content and reinforce e-learning knowledge and skill acquisition.

The methods and procedures described above were used for developing six sets of early childhood intervention e-learning lessons: Family capacity-building practices, naturalistic instruction, everyday child learning activities, interest-based child learning, early childhood contingency (cause-effect) learning, and authentic child assessment practices. The family capacity-building e-learning lessons are freely available at ectacenter.org/decrp/fcb.asp. The other ECI e-learning lessons are freely available at ecpcprofessionaldevelopment.org.

The e-learning lessons were all prepared using Adobe Captivate 9 (Adobe Systems Incorporated, 2015) in order to include responsive content and interactive elements (instructional video, knowledge checks, playback control, etc.). The instructional design includes multiple features and elements (roll-overs, embedded video, playback options, accessibility functions, etc.) to actively engage practitioners in learning to use ECI practices. Lessons learned from the development and evaluation of ECI performance checklists and practice guides informed the content and design of the e-learning lessons.

The e-learning lessons as well as the performance checklists and practice guides are available on an open source content management system (Word Press Foundation, 2003) that makes any product accessible on any type of mobile or nonmobile device. Two sets of the ECI products are briefly described next to provide readers descriptions of how the sources of information in Table 1 and Figure 2 were used to develop e-learning lessons.

\subsection{Family Capacity-Building E-Learning Lessons}

The agents of provision of ECI practices are often parents and other family members rather than practitioners, where practitioners build family capacity to use ECI practices with their children. Family capacity-building refers to ECI practitioner use of methods and strategies for promoting parents' and other family members' abilities to provide young children development-enhancing learning opportunities (Dunst and Swanson, 2006). The foundations for the e-learning lessons are based on the fact that many practitioners do not routinely use capacitybuilding practices in their work with caregivers of young children (Dunst et al., 2014).

There are five family capacity-building e-learning lessons. The lessons are designed so that material learned in earlier lessons are the building blocks for material learned in later lessons. The foundations and content of the elearning lessons are three sets of evidence-based adult learning practices that are associated with a host of positive learner outcomes (Dunst et al., 2010; Dunst and Trivette, 2012).

The first e-learning lesson includes a brief overview of family capacity-building to introduce a practitioner or student to the meaning and intent of capacity-building practices. Lessons 2, 3, and 4 include, respectively, descriptions, illustrations, and learner exercises for each of the three sets of adult learning practices. Both microvideo and tutorial videos are used throughout the lessons. The e-learning lessons also include knowledge checks to reinforce practitioners' or students' understanding of the key characteristics of family capacity-building practices. The final lesson incorporates the content from all of the other e-learning lessons and includes extensive use of video illustrations, knowledge checks, and interactive exercises for developing learner deeper understanding 
of and ability to use family capacity-building practices. All five lessons were developed with explicit attention to the product design elements in Table 1 and Figure 2.

\subsection{Early Childhood Intervention E-Learning Lessons}

Lessons learned from developing the family capacity-building lessons were used to inform the development of five additional e-learning lessons. This included, but was not limited to, fewer lessons for each practice, more authentic e-learning exercises, and inclusion of multiple "follow-up" suggestions and resources for additional learning opportunities. The latter was described as "digging deeper" learner activities.

Each of the five ECI practices includes three lessons, all formatted in the same manner. The first lesson for each practice includes an overview of the key characteristics of a practice and the expected benefits of the practice. The second lesson uses a performance checklist of the key characteristics of a practice where most lessons include microvideos to illustrate each of the key practice characteristics. Following the illustration of each practice characteristic, a tutorial video is used to illustrate how all the key characteristics "go together" and "make up" a particular type of ECI practice. The third lesson includes multiple learner activities for using a performance checklist to analyze a series of instructional videos and a series of authentic learner exercises for a practitioner or student to use to reinforce learner understanding and mastery of a practice. The five sets of e-learning lessons constitute our most recent efforts to adhere to all of the design features described in this paper.

\section{Product Evaluation}

Whenever possible, we sought practitioner and family member input on all of the products, where suggestions and feedback were used to inform changes and improvements in the e-learning lessons, performance checklists, and practice guides (e.g., (Swanson et al., 2006; Dunst et al., 2007; Dunst and Raab, 2007)). All three products described in this paper have been the focus of either or both field tests and evaluations to be assured they included intended characteristics and are judged as beneficial to end-users.

Evaluations of the performance checklists and practice guides focused on practitioner and family member social validity appraisals of both products. Social validity refers to both the importance and acceptability of intervention practices and the expected benefits of the practices (Foster and Mash, 1999). Research indicates that the likelihood of a practice being adopted and used by a practitioner or family member is dependent on whether the practice is judged as worth the time and effort to use to have desired outcomes (Strain et al., 2012).Dunst et al. (2016) for example, found parents' social validity judgments of interest-based child language learning practices were directly related to parents' fidelity of use of the practices and indirectly related to child language development mediated by fidelity of use of the practices. In a series of field-test evaluations of the types of performance checklists and practice guides in the e-learning lessons, we found that social validity appraisals of both products improved as a function of using end-user feedback in earlier field-tests to improve products evaluated in later field-tests (Dunst et al., 2017; Dunst, 2017a).

The e-learning lessons were field tested with six experienced ECI practitioners where feedback was used to inform changes in the lessons and the exercises used to engage practitioners in the use of ECI practices. The participants were two ECI program directors, two ECI technical assistance providers, and two ECI practitioners all with extensive experience working with young children and their families. Results indicated that different features of the e-learning lessons (instructional design, interactivity, learner exercises, video illustrations, etc.) were judged highly by all the practitioners. Participant feedback was used to inform improvements in the e-learning lessons that were the focus of evaluation as well as were used to inform the design and development of subsequently developed e-learning lessons.

\section{Conclusion}

The methods and procedures for designing, developing, and evaluating the ECI products described in this paper emerged over many years of experience working with ECI practitioners and families. Product development was informed by both the research and practice of others also interested in better designed e-learning lessons, performance checklists, and practice guides as well as our own research. The outcome was the development of the model and framework described in this paper for the systematic design of ECI products,

Although the model and framework were developed specifically for the design of ECI products, the model could be used easily as part of the design and development of products in other fields and for other purposes. The framework in Figure 2 would be especially suited for use by others inasmuch as it incorporates key elements and features of evidence-based and evidence-informed product design and practice development elements extensively investigated by product design experts (Bersin, 2004; Nye and Turner, 2007; Keengwe and Kang, 2013; Cheng et al., 2014).

\section{References}

Adobe Systems Incorporated, 2015. Adobe captivate 9.

Athanasou, J.A., 2005. Self-evaluations in adult education and training. Australian Journal of Adult Learning, 45(3): $290-303$.

Beavers, A., 2009. Teachers as learners: Implications of adult education for professional development. Journal of College Teaching \& Learning, 6(7): 25-30. Available at: https://doi.org/10.19030/tlc.v6i7.1122.

Beavers, E., A. Orange and D. Kirkwood, 2017. Fostering critical and reflective thinking in an authentic learning situation. Journal of Early Childhood Teacher Education, 38(1): 3-18. Available at: https://doi.org/10.1080/10901027.2016.1274693.

Bersin, J., 2004. The blended learning book: Best practices, proven methodologies, and lessons learned. San Francisco: Pfeiffer.

Brame, C.J., 2015. Effective educational videos. Available from http://cft.vanderbilt.edu/guides-sub-pages/effective-educational-videos.

Brenes, P., 2017. Terminology for beginners. Available from http://inmyownterms.com/wp-content/uploads/2017/06/TERMINOLOGYeBOOK.pdf.

Brunner, D., 2018. Five types of instructional videos and when to use them. Available from https://www.techsmith.com/blog/types-ofinstructional-videos/.

Buchem, I. and H. Hamelmann, 2010. Microlearning: A strategy for ongoing professional development. eLearning Papers, $21(7)$ : 1-15.

Cabré, M.T., 1999. Terminology: Theory, methods and applications. Philadelphia: John Benjamin Publishing Company. 
Cheng, B., M. Wang, A.I. Mørch, N.-S. Chen and J.M. Spector, 2014. Research on e-learning in the workplace 2000-2012: A bibliometric analysis of the literature. Educational Research Review, 11: 56-72. Available at: https://doi.org/10.1016/j.edurev.2014.01.001.

Colquhoun, H., J. Leeman, S. Michie, C. Lokker, P. Bragge, S. Hempel, K.A. McKibbon, G.-J.Y. Peters, K.R. Stevens and M.G. Wilson, 2014. Towards a common terminology: A simplified framework of interventions to promote and integrate evidence into health practices, systems, and policies. Implementation Science, 9(1): 1-6. Available at: https://doi.org/10.1186/s 13012-014-0154-4.

Dunst, C.J., 2015. Improving the design and implementation of in-service professional development in early childhood intervention. Infants \& Young Children, 28(3): 210-219. Available at: https://doi.org/10.1097/iyc.0000000000000042.

Dunst, C.J., 2016. Role of research syntheses for identifying evidence-based early childhood intervention practices. In B. Reichow, B. A. Boyd, E. E. Barton, and S. L. Odom (Eds.), Handbook of early childhood special education. Switzerland: Springer International. pp: $541-563$.

Dunst, C.J., 2017a. Parents' social validity appraisals of early childhood intervention practice guides. Journal of Educational and Developmental Psychology, 7(2): 51-58. Available at: https://doi.org/10.5539/jedp.v7n2p51.

Dunst, C.J., 2017b. Procedures for developing evidence-informed performance checklists for improving early childhood intervention practices. Journal of Education and Learning, 6(3): 1-13. Available at: https://doi.org/10.5539/jel.v6n3p1.

Dunst, C.J., 2017c. Research foundations for evidence-informed early childhood intervention performance checklists. Education Sciences, 7(4): 78. Available at: https://doi.org/10.3390/educsci7040078.

Dunst, C.J., 2018a. Foundations for the need for evidence-informed early childhood intervention performance checklists and practice guides. In C. J. Dunst (Ed.), Evidence-informed early childhood intervention performance checklists and practice guides. [Winterberry Press Monograph Series]. Asheville, NC: Winterberry Press. pp: 3-17.

Dunst, C.J., 2018b. Evidence-informed early childhood intervention performance checklists and practice guides [Winterberry Press Monograph Series]. Asheville, NC: Winterberry Press.

Dunst, C.J., M.B. Bruder and M. Espe-Sherwindt, 2014. Family capacity-building in early childhood intervention: Do context and setting matter? School Community Journal, 24(1): 37-48.

Dunst, C.J., M.B. Bruder and D.W. Hamby, 2015. Metasynthesis of in-service professional development research: Features associated with positive educator and student outcomes. Educational Research and Reviews, 10(12): 1731-1744. Available at: https://doi.org/10.5897/err2015.2306.

Dunst, C.J. and M. Espe-Sherwindt, 2017. Contemporary early intervention models, research, and practice for infants and toddlers with disabilities and delays. In J. M. Kauffman, D. P. Hallahan, \& C. P. Pullen (Eds.), Handbook of special education. 2nd Edn., New York: Routledge. pp: 831-849.

Dunst, C.J., D.W. Hamby, L.L. Wilson, M. Espe-Sherwindt and D.E. Nelson, 2017. Practitioner-informed improvements to early childhood intervention performance checklists and practice guides. REiD (Research and Evaluation in Education), 3(1): 12-27. Available at: https://doi.org/10.21831/reid.v3i1.14158.

Dunst, C.J., J. Pace and D.W. Hamby, 2007. Evaluation of the games for growing tool kit for promoting early contingency learning. Asheville, NC: Winterberry Press.

Dunst, C.J. and M. Raab, 2007. Evaluation of an evidence-based practice guide for increasing preschoolers prosocial peer interactions. Asheville, NC: Winterberry Press.

Dunst, C.J., M. Raab and D.W. Hamby, 2016. Interest-based everyday child language learning. Logopedia Magazine, Phoniatrics and Audiology, 36(4): 153-161.

Dunst, C.J. and J. Swanson, 2006. Parent-mediated everyday child learning opportunities: II. Methods and procedures. CASEinPoint, 2(1 1): $1-19$.

Dunst, C.J. and C.M. Trivette, 2012. Moderators of the effectiveness of adult learning method practices. Journal of Social Sciences, 8(2): 143148. Available at: https://doi.org/10.3844/jssp.2012.143.148.

Dunst, C.J., C.M. Trivette and D.W. Hamby, 2010. Meta-analysis of the effectiveness of four adult learning methods and strategies: Supplemental tables and references. Learning, 3(1): 91-112.

Ericsson, K.A., 2006. The influence of experience and deliberate practice on the development of superior expert performance. In K. A Ericsson (Ed.), The Cambridge handbook of expertise and expert performance. Cambridge, United Kingdom: Cambridge University Press. pp: 685-705

Foster, S.L. and E.J. Mash, 1999. Assessing social validity in clinical treatment research: Issues and procedures. Journal of Consulting and Clinical Psychology, 67(3): 308-319. Available at: https://doi.org/10.1037//0022-006x.67.3.308.

Ghirardini, B., 2011. E-learning methodologies: A guide for designing and developing e-learning courses. Rome: Food and Agriculture Organization of the United Nations.

Gobet, F., P.C. Lane, S. Croker, P.C. Cheng, G. Jones, I. Oliver and J.M. Pine, 2001. Chunking mechanisms in human learning. Trends in Cognitive Sciences, 5(6): 236-243. Available at: https://doi.org/10.1016/s 1364-6613(00)01662-4

Guo, P., 2013. Optimal video length for student engagement. Available from https://blog.edx.org/optimal-video-length-studentengagement.

Guo, P., J. Kim and R. Robin, 2014. How video production affects student engagement: An empirical study of MOOC videos. Paper Presented at the ACM Conference on Learning at Scale (L@S 2014).

Harrington, J., T.C. Reeves and R. Oliver, 2010. A guide to authentic e-learning. New York: Routledge.

Herrington, J., 2006. Authentic e-learning in higher education: Design principles for authentic learning environments and tasks. In T. Reeves \& S. Yamashita (Eds.), Proceedings of E-Learn 2006--World Conference on E-Learning in Corporate, Government, Healthcare, and Higher Education. Honolulu, HI: Association for the Advancement of Computing in Education (AACE). pp: $3164-$ 3173 .

Herrington, J., T.C. Reeves and R. Oliver, 2010. A guide to authentic e-learning. New York: Routledge.

Hug, T., 2016. Didactics of microlearning: Concepts, discourses and examples. New York: Waxmann.

Hulleman, C.S. and J. Kopp, 2012. Intervention fidelity: Models, methods, and applications. Paper Presented at the Pre-Conference Workshop at the Spring Conference of the Society for Research on Educational Effectiveness, Washington, DC.

Juwah, C., 2006. Interactions in online education: Implications for theory and practice. New York: Routledge.

Karagiannidis, C., P. Politis and I. Karasavvidis, 2014. Research on e-learning and ICT in education: Technological, pedagogical and instructional perspectives. New York: Springer.

Keengwe, J. and J.-J. Kang, 2013. A review of empirical research on blended learning in teacher education programs. Education and Information Technologies, 18(3): 479-493. Available at: https://doi.org/10.1007/s 10639-01 1-9182-8.

Khan, B.H., 2005. Managing e-learning: Design, delivery, implementation, and evaluation. Hershey, PA: Information Science Publishing.

Lidwell, W., K. Holden and J. Butler, 2003. Universal principles of design. Beverly, MA: Rockport Publishers.

Morrison, G.R., S.M. Ross and J.E. Kemp, 2007. Designing effective instruction. 5th Edn., Hoboken, NJ: John Wiley \& Sons.

Nelson, J. and C. Campbell, 2017. Evidence-informed practice in education: Meanings and applications. Educational Research, 59(2): 127-135. Available at: https://doi.org/10.1080/00131881.2017.1314115.

Nye, C. and H. Turner, 2007. Developing evidence-based products using the systematic review process. Austin, TX. National Center for the Dissemination of Disability Research.

Oblinger, D.G. and M.K. Maruyama, 1996. Distributed learning. Boulder, Co: EDUCAUSE Publications.

Raab, M. and C.J. Dunst, 2006. Checklists for promoting parent-mediated everyday child learning opportunities. CASEtools, 2(1): 1-9.

Rabin, B.A. and R.C. Brownson, 2012. Developing the terminology for dissemination and implementation research. In R. C. Brownson, G. A. Colditz, \& E. K. Proctor (Eds.), Dissemination and implementation research in health. New York: Oxford University Press. pp: 2351.

Reeves, T.C., J. Herrington and R. Oliver, 2002. Authentic activities and online learning. In T. Herrington (Ed.), Research and development in higher education: Quality conversations. Hammondville, New South Wales, Australia: Higher Education Research and Development Society of Australasia (HERDSA), 25: 562-567. 
Strain, P.S., E.E. Barton and G. Dunlap, 2012. Lessons learned about the utility of social validity. Education and Treatment of Children, 35(2): 183-200. Available at: https://doi.org/10.1353/etc.2012.0007.

Sukkar, H., C.J. Dunst and J. Kirkby, 2017. Early childhood intervention: Working with families of young children with special needs. Abingdon, Oxfordshire: Routledge.

Swanson, J., N. Roper, M. Raab and C.J. Dunst, 2006. Practitioner judgments of the usefulness of contextually mediated practices training activities. CASEinPoint, 2(9): 1-7.

Thaiss, C. and T.M. Zawacki, 2006. Engaged writers and dynamic disciplines: Research on the academic writing life. Portsmouth: Boynton/Cook.

Wagner, E., 1997. Interactivity: From agents to outcomes. In T. Cyrs (Ed.), Teaching and learning at a distance: What it takes to effectively design, deliver, and evaluate programs. San Francisco: Jossey-Bass. pp: 19-26.

Ward, P., N.J. Hodges, A.M. Williams and J.L. Starkes, 2004. Deliberate practice and expert performance: Defining the path to excellence. In A. M. Williams \& N. J. Hodges (Eds.), Skill acquisition in sport: Research, theory and practice. New York: Routledge. pp: $231-258$.

Wilson, C., 2013. Credible checklists and quality questionnaires: A user-centered design method. Waltham, MA: Morgan Kaufman.

Wistia Learning Center, 2016. How long should your next video be? Available from https://wistia.com/learn/marketing/optimal-videolength/.

Wolery, M., 2011. Intervention research: The importance of fidelity measurement. Topics in Early Childhood Special Education, $31(3): 155-$ 157. Available at: https://doi.org/10.1177/0271121411408621.

Word Press Foundation, 2003. Word press system software. Available from www.WordPress.com. 